
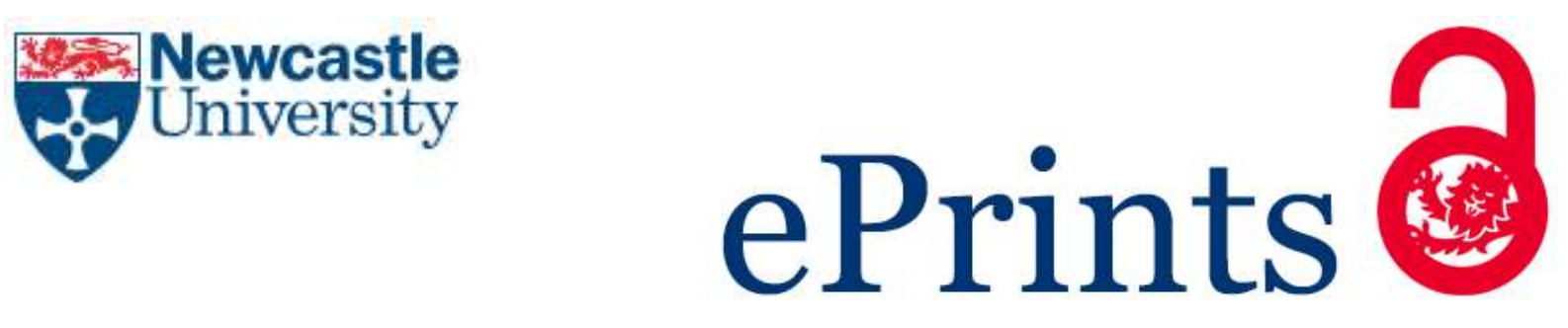

Hunter N, Muirhead CR, Bochicchio F, Haylock RGE. Calculation of lifetime lung cancer risks associated with radon exposure, based on various models and exposure scenarios. Journal of Radiological Protection 2015, 35(3), 539539.

Copyright:

(C)2015 IOP Publishing

IOP Science allows for 'Self-archiving of the accepted version of an article (green OA) after a maximum 12-month embargo period on all journals'.

DOI link to article:

http://dx.doi.org/10.1088/0952-4746/35/3/539

Date deposited:

$24 / 08 / 2015$

Embargo release date:

17 June 2016

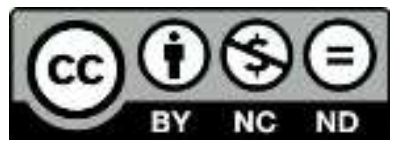

This work is licensed under a

Creative Commons Attribution-NonCommercial-NoDerivatives 4.0 International licence 


\title{
Calculation of lifetime lung cancer risks associated with radon exposure, based on various models and exposure scenarios
}

\author{
Nezahat Hunter $^{\text {a,1, }}$, Colin R Muirhead ${ }^{\mathrm{b}}$, Francesco Bochicchio ${ }^{\mathrm{c}}$, Richard GE \\ Haylock $^{\text {a }}$ \\ ${ }^{a}$ Public Health England, Centre for Radiation, Chemical and Environmental Hazards, \\ Chilton, Didcot, Oxon OX11 0RQ, UK. \\ ${ }^{\mathrm{b}}$ Newcastle University, Institute of Health and Society, Newcastle upon Tyne, NE2 \\ $4 \mathrm{AX}, \mathrm{UK}$ \\ ${ }^{\mathrm{c}}$ Istituto Superiore di Sanità (Italian National Institute of Health), Dipartimento di \\ Tecnologie e Salute (Dept. of Technology and Health), Viale Regina Elena, 299, \\ 00161 Rome, Italy,
}

1: To whom correspondence should be addressed: Nezahat.Hunter@phe.gov.uk 


\section{ABSTRACT}

The risk of lung cancer mortality up to 75 years of age due to radon exposure has been estimated for both male and female continuing, ex- and never-smokers, based on various radon risk models and exposure scenarios. We used risk models derived from (i) the BEIR VI analysis of cohorts of radon-exposed miners, (ii) cohort and nested case-control analyses of a European cohort of uranium miners and (iii) the joint analysis of European residential radon case-control studies. Estimates of the lifetime lung cancer risk due to radon varied between these models by just over a factor of 2 and risk estimates based on models from analyses of European uranium miners exposed at comparatively low rates and of people exposed to radon in homes were broadly compatible. For a given smoking category, there was not much difference in lifetime lung cancer risk between males and females. The estimated lifetime risk of radon-induced lung cancer for exposure to a concentration of $200 \mathrm{~Bq} \mathrm{~m}{ }^{-3}$ was in the range $2.98 \%-6.55 \%$ for male continuing smokers and $0.19 \%-0.42 \%$ for male neversmokers, depending on the model used and assuming a multiplicative relationship for the joint effect of radon and smoking. Stopping smoking at age 50 years decreases the lifetime risk due to radon by around a half relative to continuing smoking, but the risk for ex-smokers remains about a factor of 5-7 higher than that for never-smokers. Under a sub-multiplicative model for the joint effect of radon and smoking, the lifetime risk of radon-induced lung cancer was still estimated to be substantially higher for continuing smokers than for never smokers. Radon mitigation - used to reduce radon concentrations at homes - can also have a substantial impact on lung cancer risk, even for persons in their 50s; for each of continuing smokers, ex-smokers and never-smokers, radon mitigation at age 50 would lower the lifetime risk of radon- 
induced lung cancer by about one-third. To maximise risk reductions, smokers in high-radon homes should both stop smoking and remediate their homes.

\section{Introduction}

The International Agency for Research on Cancer [1] has declared radon to be a cause of lung cancer in humans, based on the results of experimental and epidemiological studies. Studies of underground miners exposed to radon [2] and studies of persons exposed to radon in homes [3-6] have shown that radon is a major cause of lung cancer. In addition, a recent joint analysis of cohorts of uranium miners from three European countries (the Czech Republic, France and Germany) and a nested casecontrol study within these cohorts - both conducted under the European Commission (EC)-supported Alpha-Risk project - allow examination of the risks of radon-induced lung cancer based on accurate radon measurements and also allow examination of the modifying effect of smoking [7-9]. The results from these new studies of miner data are in agreement with those from the international miner studies [2] and also from a joint analysis of European residential radon studies [4]. All of these studies have also demonstrated that the evidence for this raised risk is particularly strong among smokers, although a raised risk has also been seen among never-smokers.

The aim of this paper is to estimate the lifetime risk of lung cancer mortality associated with radon exposure, based on various models derived from studies of occupational and residential radon exposure and on various exposure scenarios. In particular, we examine the impact of lung cancer risk of mitigation measures to reduce radon levels, especially in homes with high radon concentrations. 
Furthermore, we also consider the effect of smoking - the major cause of lung cancer on estimates of radon-induced lung cancer risk.

\section{Materials and Methods}

\section{Radon Risk Models}

Various radon risk models are considered from epidemiological studies of radonexposed miners and people exposed to radon at home. The lung cancer risk models from the miner studies were based on male workers occupationally exposed to radon, whereas the risk model based on residential radon studies was based on populations including both males and females. The analyses considered are: the BEIR VI joint analysis of 11 cohort studies of radon-exposed miners [2]; the joint analysis of three European cohorts of uranium miners, in the Czech Republic, France and Germany [7]; the joint analysis of three case-control studies nested within the European miner cohorts [8, 9]; and the joint analysis of 13 European residential radon studies [4]. These analyses and the associated radon risk models are briefly summarised here.

\section{BEIR VI model:}

The BEIR VI Committee analysed a pooled data set from 11 cohort studies of radonexposed miners in China, Canada, Europe, USA and Australia [2]. The analysis included more than 2,620 lung cancer deaths among 60,570 exposed miners followed for nearly 1.2 million person years. The Committee derived two models to assess the risk of radon-induced lung cancer, based on either duration of exposure (exposureage-duration, EAD model) or the average radon concentration (Exposure-AgeConcentration, EAC model). Under both models, the baseline risk was stratified by miner cohort, age group, other occupational exposures and ethnicity. Also, under both 
models, radon exposure has a multiplicative effect on the baseline rate of lung cancer and the excess relative risk (ERR, i.e. the relative risk minus 1) decreases with increasing time since exposure and increasing attained age. In addition, both models consider various exposure time intervals prior to lung cancer death; the cumulative radon exposure $w$, was defined using three exposure time windows, that is $w=w_{5-14}+$ $w_{15-24}+w_{25+}$, corresponding to exposures received 5-14, 15-24 and 25 years or more prior to the attained age respectively (i.e. $w_{5-14}$, refers to the mean exposure accumulated in the period between 5 years prior to attained age and 14 years prior to attained age). These models do not include an adjustment for smoking [2]. The EAC model is considered here because - relative to the EAD model - it allows easier comparison with findings from studies of residential radon. Since exposure rates in homes (less than 0.5 Working Levels, WL) are lower than those in mines, the coefficient for exposure rate in the EAC model is equated to 1 . The following simplified EAC model is considered here; the parameter values in Eq.1 are taken from BEIR VI (2) and expressed as:

$$
\mathrm{ERR}=\beta\left(w_{5-14}+0.78 w_{15-24}+0.51 w_{25+}\right) \theta_{\text {age }} \lambda_{\mathrm{z}}
$$

where $\beta$ is the slope of the exposure-risk relationship $(\beta=0.0768) ; w_{5-14}, w_{15-24}$ and $w_{25+}$ represent cumulative radon exposures (expressed in Working Level Months (WLM)) received during time windows 5-14 years, 15-24 years and 25+ years or more prior to the attained age, respectively, $\theta_{\text {age }}$ is the attained age-related modification factor (categorised as: $\theta_{\text {age }<55}=1 ; \theta_{\text {age } 55-64}=0.57 ; \theta_{\text {age } 65-74}=0.29 ; \theta_{\text {age } 75+}$ $=0.09)$ and $\lambda_{z}$ represents the effect of exposure rate $\left(\lambda_{z}=1\right)$. Under this model, exposures received during the previous 5 years are assumed not to increase the risk of 
lung cancer. Furthermore, the modelling took account of the temporal pattern of exposures, rather than simply when they started and when they ended. Here, as in the other models described below, the ERR was assumed to be the same for males and females.

\section{Joint European miner cohort model:}

A joint analysis of cohort studies of uranium miners in the Czech Republic, France and Germany was conducted under the EC-supported Alpha-Risk project and is described in detail elsewhere [7]. The combined analysis from three European countries included 1,543 lung cancer deaths among 50,149 uranium miners exposed to relatively low levels of radon and followed for nearly 1.3 million person years during 1946-1999.

The joint European cohort analysis reported a strong modifying effect on the ERR of time since exposure, attained age and exposure rate, in agreement with the BEIR VI analysis. Risk modelling of the European miner cohort data used a similar approach to the BEIR VI-style EAC model, with some modifications. In particular, the European cohort analysis allows for 5 rather than 4 attained age categories and different time since exposure windows, namely 5-19, 20-34 and 35+ years. In addition, the ERR in the European miners' cohort model was adjusted for calendar year, birth year and study through stratification of the baseline rates. As in BEIR VI, the exposure rate in the EAC type model is also equated to 1 for the European cohort model and the model is expressed as:

$$
\mathrm{ERR}=\beta\left(w_{5-19}+0.42 w_{20-34}+0.14 w_{35+}\right) \theta_{\text {age }}
$$


where $\beta=0.052 ; w$ is the exposure during various time windows prior to the attained age (expressed in WLM) with modification by attained age; $\theta_{\text {age }}<45=1 ; \theta_{\text {age }} 45-54=0.66$ $; \theta_{\text {age }} 55-64=0.39 ; \theta_{\text {age } 65-74}=0.33 ;$ and $\theta_{\text {age }} 75+=0.49$.

Data on smoking were not available for the full miner cohorts. Hence, smoking was not incorporated into this risk model. Further details of this model and its implementation are presented elsewhere [7].

\section{Joint European miner nested case-control model:}

Case-control studies nested within the three European cohorts of uranium miners were conducted in order to investigate the joint association of radon and smoking. The European miner nested case-control data included a total of 1,476 lung cancer cases and 3,389 controls with smoking information. More details of the data can be found elsewhere $[8,9]$.

A modified version of the BEIR VI-EAC model with additional adjustment for smoking was applied to these data unrestricted by the range of exposures [8,9]. It was concluded that the ERR decreased with increasing time since exposure and attained age, but there was no statistically significant effect for exposure rate. The model used here is similar to that model given by Hunter et al [9] and the model parameters are based on two time since exposure windows, namely 5-24 and 25+ years, rather than three because the ERR/WLM estimates for exposures 5-14 and 1524 y previously are similar $[8,9]$. This model also includes an effect of attained age, because Hunter et al found that the ERR/WLM decreased significantly with increasing attained age [9]. Thus, the risk model is expressed here as model 1:

$$
\mathrm{ERR}=\beta\left(w_{5-24}+0.12 w_{25+}\right) \theta_{\text {age }}
$$


where $\beta=0.041 ; \theta_{\text {age }<55}=1 ; \theta_{\text {age }} 55-64=0.93 ; \theta_{\text {age }} 65-74=0.32 ; \theta_{\text {age } 75+}=0.66$.

An alternative model based on these data is also considered here: namely, a constant linear ERR model with modifying effects of time since first exposure. Further details of the derivation of this model - referred to here as model 2 - are presented elsewhere (9); it is defined as follows:

$$
\mathrm{ERR}=\beta w[\exp \alpha(\operatorname{tsfx}-30)]
$$

where $w$ is the total cumulative exposure $\left(\mathrm{w}=w_{5-24}+0.12 w_{25+}\right), \alpha$ is the parameter associated with the effect of time since first exposure (tsfx), expressed in years, and the parameter coefficients are $\beta=0.013, \alpha=-0.078$. This model was also derived using data unrestricted by the range of exposures. Equation (3b) is a simplified version of the model derived by Hunter et al [9]; specifically, it does not take account of the modifying factor of exposure rate because residential radon exposure rates would normally be below $0.1 \mathrm{WL}$, which is equivalent to $800 \mathrm{~Bq} / \mathrm{m}^{-3}$. Results from analysing the joint effects of radon and smoking showed that the ERR was higher among never-smokers than among current smokers, although these differences were not statistically significant $[8,9]$. Thus, there is some evidence that radon and smoking have a sub-multiplicative effect on lung cancer risk, as in the BEIR VI analysis [2]. Consequently, both a multiplicative model and a sub-multiplicative model for the effects of smoking and radon are used here in the risk calculations based on the European nested case-control miner data (Eq.3b). Under a multiplicative model, the same ERR is applied to smokers and non-smokers. Under a submultiplicative model, the ERR coefficient $\beta$ in equation $3 \mathrm{~b}$ is multiplied by a factor of 1.5 for non-smokers, so giving a value of 0.026 . Since the overall estimate ignoring 
smoking status is the same as the estimate for current smokers, no adjustment factor is applied for current smokers. However, as a sensitivity check, we multiplied the value of $\beta$ in equation $3 b$ by 0.75 for current smokers to assess how the lifetime calculations may change. Because of the limitations of the information on smoking from the miner case-control analysis, no adjustment factor is applied for ex-smokers.

\section{Joint European residential radon model:}

The joint analysis of 13 case-control studies of residential radon and lung cancer in nine European countries included a total of 7,148 subjects with lung cancer and 14,208 subjects without lung cancer (controls), with detailed smoking histories for all subjects [3, 4]. The analysis focused on the mean radon concentration in homes occupied during the period 5-34 years prior to diagnosis of the lung cancer. The authors of this analysis found no evidence of the ERR differing according to age and defined the relation between residential radon exposure and lung cancer using a simple linear model:

$$
\mathrm{ERR}=\beta \times \text { Radon }
$$

where $\beta$ is the slope of the exposure-risk relationship and Radon is the mean radon concentration in the homes (expressed as $\mathrm{Bq} \mathrm{m}^{-3}$ ) during the previous 5-34 years. After correction for random uncertainties in measurements of radon concentrations, the estimated ERR of lung cancer per $100 \mathrm{~Bq} \mathrm{~m}^{-3}$ was 0.16 (95\% CI: 0.05-0.31). There was no evidence that the ERR depended on the smoking status, although the point estimate of the ERR was greater for ex-smokers and non-smokers than for current smokers [4]. Based on a constant value for the ERR across smoking categories, the excess absolute risk of lung cancer due to radon was much greater 
among current and recent ex-smokers than among lifelong non-smokers [3, 4]. Also, since the joint analysis of European residential studies found no significant difference in the ERR between males and females [4], the same value for the ERR has been applied to gender-specific baseline rates.

\section{Equating the Units of Exposure from Miners and Residential Studies}

Findings from epidemiological studies of miners are generally expressed in terms of cumulative exposure in WLM. However, studies of radon exposure in homes are generally based on time-weighted average radon concentrations in $\mathrm{Bq} \mathrm{m}^{-3}$. In order to equate these exposure measures, it has been assumed here that on average people spend 7000 hours at home per year and that the equilibrium factor for radon in homes is 0.4. Taken together with the estimated average residential radon concentration of $20 \mathrm{~Bq} \mathrm{~m}^{-3}$ in the $\mathrm{UK}$, the corresponding average exposure rate in terms of WLM per year is:

$0.09 \mathrm{WLM} / \mathrm{y}=\left(20 \mathrm{~Bq} \mathrm{~m}^{-3}\right) \times(7000$ hours $) \times(0.4) \times\left(1.5710^{-6} \mathrm{WLM}\right)$

Further details of this conversion are explained in detail elsewhere [9]. Thus 30 years' exposure in a home with a residential concentration of $100 \mathrm{~Bq} \mathrm{~m}^{-3}$ equates to a cumulative exposure of 13.2 WLM [9]. Using this conversion factor, the ERR per $100 \mathrm{~Bq} \mathrm{~m}^{-3}$ of 0.16 from the joint European residential analysis corresponds to an ERR of $0.16 / 13.2=0.012$ per WLM. Thus the model used here is as follows:

$$
\mathrm{ERR}=0.012 \times \text { Radon }_{5-34}
$$


where Radon $_{5-34}$ is the cumulative exposure in the preceding 5-34 years, expressed in WLM.

Implicit in this model is the idea that the exposure in any year during the preceding 534 years has the same effect on the ERR. To allow for the possibility that exposures in more recent years carry more weight than more distant exposures, an alternative approach was also considered, under which the relevant exposure period was taken to be the previous 5-24 years. In this instance, $100 \mathrm{~Bq} \mathrm{~m}^{-3}$ can be equated to $0.667 \mathrm{x} 13.2$ $=8.8 \mathrm{WLM}$ and the ERR per $100 \mathrm{~Bq} \mathrm{~m}^{-3}$ of 0.16 from the joint European residential analysis corresponds to an ERR of $0.16 / 8.8=0.018$ per WLM, i.e.

$$
\mathrm{ERR}=0.018 \times \text { Radon }_{5-24}
$$

\section{Measures of Lifetime Risk}

Several measures have been developed to quantify the risk over a lifetime that an individual will develop or die from a specific disease caused by an exposure. These measures include the excess lifetime risk (ELR), the risk of exposure-induced death (REID), loss of life expectancy (LLE) if death occurs and lifetime-attributable risk (LAR), i.e. the fraction of exposure-induced deaths in the population. More information about these measures can be found in elsewhere [10, 11]. Although all these measures have some benefit in risk assessment, the risk of exposure-induced death (REID) is the most commonly preferred quantity for radiation risk assessment and has been used by several scientific committees [12-16]. REID represents the lifetime risk that an individual (classified by, say, age group, gender or smoking status) in the population will die from a cancer caused by his or her radiation exposure, irrespective of whether that person might have died subsequently from the same cause at a later time. This is calculated from a life table, based on the difference 
between the cause-specific death rates for exposed and unexposed general populations of a given gender and a given age at exposure. REID was used here to estimate lifetime risks for lung cancer associated with radon exposure (see Appendix for a more detailed explanation).

The calculation of REID depends on the choice of the baseline gender-age specific lung cancer and all causes mortality rates. Since the lung cancer deaths are strongly dependent on smoking, it is desirable to use information on mortality rates for lung cancer and all causes among current smokers, ex-smokers and never-smokers by age categories and gender. However, this information is limited for many countries, including those in Europe. Consequently, the calculations presented here have been performed using data from the USA in 2004 on lung cancer and all-cause mortality rates (expressed as the risk of death in the following 10 years), given separately for current, ex- and never-smokers and also for males and females within 5-year age intervals [17]. We have also used information on smoking status among adults in the USA in 1993 [18]; specifically, $57.7 \%$ of females and $41.3 \%$ of males were never smokers, $19.5 \%$ of females and $30.3 \%$ of adult males were ex-smokers and $22.8 \%$ of females and $28.4 \%$ of males were smokers. The ERR from various models defined previously were then incorporated into the life table calculations described in the Appendix, in order to estimate lifetime lung cancer risks from radon exposure.

\section{Exposure scenarios}

People living in homes with high radon levels often carry out remedial action. Hence, as well as investigating the lung cancer risks predicted as a consequence of constant radon exposures, it is important to investigate the impact of reductions in radon exposures. Specifically, we have investigated scenarios under which mitigation occurs when an individual is aged either 50 or 60 years, the radon concentration in the 
home prior to mitigation was 200,400 or $600 \mathrm{~Bq} \mathrm{~m}^{-3}$, and the radon concentration after mitigation is $100 \mathrm{~Bq} \mathrm{~m}^{-3}$.

\section{Results}

\section{Lifetime risk calculations for various radon risk models}

Table 1 shows estimates of REID for a European population. These calculations are based on exposure from age 30 years up to 75 years to a constant radon concentration of $20,50,80,200,400$ or $600 \mathrm{~Bq} \mathrm{~m}^{-3}$ and using various risk models as defined previously. Those concentrations equate to annual exposures of $0.09,0.22,0.35,0.88$, 1.76 and $2.64 \mathrm{WLM} / \mathrm{y}$ respectively using the conversion factors described in equation

5. Risks are presented separately for males and females, and for continuing smokers, never-smokers and persons who stopped smoking at age 50 years.

A multiplicative joint association for radon exposure and gender was assumed in Table 1. Since the baseline lung cancer rates for females are only slightly lower than those for males in the case of continuing smokers and ex-smokers and slightly higher in the case of never-smokers, the estimates of REID do not differ greatly between males and females (Table 1).

The lifetime risk of radon induced lung cancer death by age 75 years for a male neversmoker, assuming that this individual has lived from age 30 years in a home with a radon concentration of $50 \mathrm{~Bq} \mathrm{~m}^{-3}$ (the European long-term average), is estimated to be in the range $0.05 \%$ to $0.11 \%$, according to the risk model used. These estimates rise to $0.19 \%-0.42 \%$ for male never-smokers in homes with a radon concentration of 200 $\mathrm{Bq} \mathrm{m}^{-3}$ and to $0.39 \%-0.85 \%$ at $400 \mathrm{~Bq} \mathrm{~m}^{-3}$ (Table 1). For a male continuing smoker, the lifetime risk based on residence from age 30 in a home with a radon concentration 
of $50 \mathrm{~Bq} \mathrm{~m}^{-3}$ is estimated to be in the range $0.76 \%$ to $1.70 \%$ and rises to $2.98 \%$ $6.55 \%$ at $200 \mathrm{~Bq} \mathrm{~m}^{-3}$ and to $5.82 \%-12.5 \%$ at $400 \mathrm{~Bq} \mathrm{~m}^{-3}$. For a male who stopped smoking at age 50 years, the lifetime risk of radon-related lung cancer death is around half of that for a male continuing smoker with the same radon exposure, but is considerably higher than the corresponding risk for a male never-smoker, irrespective of the risk model used. Similar patterns are seen in females (Table 1 and Figure 1). By way of comparison, the estimated baseline lifetime risk of lung cancer death by age 75 years old is $1.1 \%$ for male and $0.85 \%$ for female smokers; $0.51 \%$ for male and $0.40 \%$ for female ex-smokers; and $0.07 \%$ for male and $0.09 \%$ for female neversmokers.

Considering the various risk models used, REID is consistently highest for the BEIR VI EAC model and lowest for the model based on the European residential analysis and for model 2 from the European nested case-control miner analysis.

The results in Table 1 are based on radon concentrations in homes occupied during previous 5-34 years, using the model described in Equation 6. If the relevant exposure period were taken to be the previous 5-24 years, as modelled by Equation 7, then the values for REID are around $10 \%$ higher than the corresponding values in Table 1 (results not shown).

Sensitivity analysis for multiplicative and sub-multiplicative interaction between radon and smoking under a European nested case-control miner model

Using model 2 from the European nested case-control miner analysis (Eq. 3b), Table 2 shows estimates of REID in both male and female continuing smokers and neversmokers, based on multiplicative and sub-multiplicative models for the joint effect of radon and exposure and smoking. The estimates under a sub-multiplicative model for 
the joint effects of radon and smoking are smaller for continuing smokers and larger for never-smokers than the corresponding estimates under a multiplicative model. However, even under a sub-multiplicative model, REID is substantially higher for continuing smokers than for never-smokers (Table 2), reflecting the much higher baseline lung cancer risk in the former group. For example, the REID for a male continuing smoker in a home with a radon concentration of $100 \mathrm{~Bq} \mathrm{~m}^{-3}$ is about 14 times higher than that for a male never-smoker under a multiplicative model and is about 8 times higher under a sub-multiplicative model. The corresponding ratios for females are 10 and 5 respectively. The same ratios also apply to other radon concentrations, at least approximately, due to the linearity of ERR with exposure.

\section{Investigation of exposure scenarios using various radon risk models}

Tables 3 and 4 present estimates of REID, both with and without radon mitigation at either age 50 years or age 60 years. As before, there is not much difference between males and females in the REID estimates, either with or without radon mitigation. For a male continuing smoker living in a home with a radon concentration of 200,400 or $600 \mathrm{~Bq} \mathrm{~m}^{-3}$, doing nothing translates into an estimated REID of $2.98 \%, 5.82 \%$ or 8.53\% respectively, based on the model derived from the European residential analysis. However, mitigating for radon at age 50 years while continuing to smoke reduces this lifetime risk by nearly $20 \%$ (to $2.40 \%$ ) for an initial concentration of 200 $\mathrm{Bq} \mathrm{m}^{-3}$, by $30 \%$ (to $4.15 \%$ ) for $400 \mathrm{~Bq} \mathrm{~m}^{-3}$ and by $30 \%$ (to $5.86 \%$ ) for $600 \mathrm{~Bq} \mathrm{~m}^{-3}$ (Table 3). The corresponding reductions in REID based on mitigating for radon at age 60 rather than age 50 are smaller, namely by nearly $6 \%$ (to 2.81 ) for $200 \mathrm{~Bq} \mathrm{~m}^{-3}$, by $10 \%$ (to $5.33 \%$ ) for $400 \mathrm{~Bq} \mathrm{~m}^{-3}$ and by $10 \%$ (to $7.75 \%$ ) for $600 \mathrm{~Bq} \mathrm{~m}^{-3}$. The percentage reductions in REID for never smokers are generally similar to those for continuing smokers. 
Combining radon mitigation and quitting smoking, both at age 50, reduces the lifetime risk relative to continuing smoking and not undertaking radon remediation by nearly $60 \%$ (to $1.09 \%$ ) for an initial concentration of $200 \mathrm{~Bq} \mathrm{~m}^{-3}$, by $70 \%$ (to $1.90 \%$ ) for $400 \mathrm{~Bq} \mathrm{~m}^{-3}$ and by $70 \%$ (to $2.69 \%$ ) for $600 \mathrm{~Bq} \mathrm{~m}^{-3}$, using the model derived from the European residential analysis. The corresponding reductions in the lifetime risk based on mitigating for radon at age 60 (rather than age 50) and stopping smoking at age 50 are slightly smaller, namely by nearly $60 \%$ (to $1.29 \%$ ) for $200 \mathrm{~Bq} \mathrm{~m}^{-3}$, by $60 \%$ (to $2.47 \%$ ) for $400 \mathrm{~Bq} \mathrm{~m}^{-3}$ and by $60 \%$ (to $3.63 \%$ ) for $600 \mathrm{~Bq} \mathrm{~m}^{-3}$ (Table 3). Whilst the absolute values for the lifetime risk vary to some degree between risk models, the percentage reductions associated with radon mitigation or stopping smoking do not vary greatly according to the model used.

\section{Discussion}

Lung cancer is the most common cause of death from cancer among men and the third most common cause among women in Europe; specifically, it is responsible for nearly $26 \%$ of all male cancer deaths and $13 \%$ of all female cancer deaths [19]. The lifetime risk estimates presented here provide a common means of comparing estimates of radon-induced risks based on various published exposure-response risk models derived from the cohort and case-control of miners and residential case-control studies in the general population. The risk of exposure-induced death (REID) has been calculated here to evaluate the lifetime risk up to 75 years only. This decision has been influenced by issues with death certification at older ages and, to some extent, by limitations on the availability of information on mortality rates for smoking-specific groups (although there is a 75+ group in the Woloshin paper [17]). Furthermore, the BEIR VI calculations were also based on ages $<75$ years [2]. 
Lifetime risk estimates for lung cancer arising from radon exposure have been reported previously for populations within Europe (such as the UK, France and Germany), USA, Canada, and combined Euro-American and Asian populations [12, 14, 20-24]. These estimates differ from those presented here in several aspects. First, most of the previous assessments were based on BEIR VI risk models developed using studies of miners [2] or on risks estimated from the European joint analysis of residential case-control studies [3,4]. In contrast, the present calculations are based on not only these models, but also on models derived from recently published combined analyses of European uranium miner cohorts and case-control studies nested within these cohorts. Second, the present assessment focused on REID from radon, rather than the excess lifetime risk (ELR). Vaeth and Pierce [10] have discussed special cases where ELR is ill-defined and suggested that REID is the preferred quantity for assessing radiation-induced risks. Third, the present analysis used baseline rates for all-cause and lung cancer mortality from the US, while other studies used mortality rates for combined Euro-American and Asian populations [22], Switzerland and Germany [21] and Canada [24]. Baseline lung cancer rates differ considerably between countries $[19,25]$. Under ERR models of the type considered here, these differences can be expected to be reflected proportionally in the estimates of radonattributable lung cancers. Fourth, the lifetime risks presented here are based on age and gender-specific rates calculated separately for continuing smokers, ex-smokers and never-smokers. In contrast, previous studies have considered ever-smokers and never-smokers or both ever- and never-smokers combined [14, 20-24].

The ratio of the lifetime risks among continuing smokers and never smokers reported here (i.e. 8-10 for females and 15-16 for males) is smaller than that reported in the European residential analysis (i.e. about 24 for females and males combined [4]). 
This is because the residential analysis did not adjust for the effects of competing causes of death and also because of the differences in the smoking-specific baseline rates used. Furthermore, the US Environmental Protection Agency (EPA) reported a ratio of about 5 for females and 6 for males using a modified version of the BEIR VI risk model [14]. This is somewhat smaller than the ratio based on the BEIR VI model used here (i.e. 16). This difference in the ratio can be explained by the choice of model i.e. EPA's use of a modified BEIR VI risk model, as well as the groups that are being compared, i.e. ever (rather than continuing) smokers versus never smokers.

\section{Choice of risk model}

For a given exposure scenario, smoking status and gender, the estimated lifetime risk of radon-induced lung cancer varies between risk models by around a factor of just over 2. The model based on the combined analysis of European residential radon studies provides the lowest risk estimates, while the BEIR VI-EAC model from the joint analysis of 11 international cohorts of miners gives the highest risk estimates. The lifetime risk estimates based on the European cohort and nested case-control miner models fall between these values. However, model 2 (Eq.3b) based on the European nested case-control miner analysis gives values for REID only slightly greater than those from the model based on the European residential analysis. The differences in REID between models may reflect, at least in part, differences between miner and residential populations in patterns of exposure by time and age. In particular, unlike the model based on the European residential analysis, the ERRs under the models based on data for miners vary with time since exposure and attained age. 
It is beyond the scope of this work to calculate quantitative estimates of uncertainty in the REID estimates presented here. The REID estimates are subject to considerable uncertainty and the various sources of uncertainties in risk estimates have been addressed elsewhere $[11,14]$. For example, the age and time-constant ERR model based on the joint analysis of European residential radon case-control studies contrasts with the ERR model involving age and time since exposure windows, based on miner data. Furthermore, the parameter estimates in these models also have uncertainties, which will disseminate through the models and affect the overall uncertainty. Other sources of uncertainty include the potential for unmeasured confounding and the impact of modifying factors.

\section{Joint effect of smoking and radon}

Cigarette smoking is the leading cause of lung cancer, accounting for approximately $90 \%$ of lung cancer cases in Europe and other countries where cigarette smoking is common $[26,27]$. Hence, it is important to consider how smoking might modify risks due to radon. Information on smoking from the studies of miners is more limited than that from the residential radon studies. In both occupational and residential analyses, the point estimates of the ERR for radon were higher in non-smokers than smokers, but these differences were not statistically significant $[1,3,8,9]$. Consequently, we examined both multiplicative and sub-multiplicative models for the joint effect of smoking and radon here. Whilst the magnitude of the relative risks differed between the miner and residential analyses, the overall patterns in radon risk were generally similar in both instances.

For a given smoking category, there is not much difference in REID between males and females. This is because the smoking-category specific baseline rates in the US 
do not differ between males and females. Under a multiplicative relationship for the joint effect of radon exposure and smoking, the lifetime risk of radon-induced lung cancer is substantially higher for continuing smokers than for never-smokers, by a factor of around 9-16 depending on the risk model. Quitting smoking at age 50 years would decrease the lifetime risk by around a half compared to that for continuing smokers with the same radon exposure, but the risk for ex-smokers would remain about a factor of 5-7 higher than that for never-smokers.

Under a sub-multiplicative model for the joint effect of smoking and radon, the lifetime risk due to radon is slightly smaller for continuing smokers and larger for never-smokers compared to the corresponding estimates based on a multiplicative model. Nevertheless, under a sub-multiplicative model, the lifetime risk of radoninduced lung cancer is still substantially higher (by a factor of around 5-7) for continuing smokers than for never-smokers. This is because smokers have much higher rates of lung cancer than non-smokers in the absence of radon exposure.

\section{Effect of radon mitigation}

Consideration of alternative exposure scenarios indicates that, even for persons in their 50s, radon mitigation of their homes could have a notable impact on their lifetime risk of radon-induced lung cancer mortality. In particular, for each of continuing smokers, ex-smokers and never-smokers, radon mitigation at age 50 would lower the lifetime risk of radon-induced lung cancer by about one-third. The impact of radon mitigation at age 60 years is smaller, namely a reduction in REID of around 10\%. Clearly, stopping smoking has a considerable impact in reducing lung cancer risks. Nevertheless - among continuing smokers, ex-smokers and never-smokers measures to reduce radon exposure can also be important in reducing these risks. For 
example, both undertaking radon mitigation and quitting smoking at age 50 reduces REID by around $60-70 \%$, compared to no mitigation and continued smoking. Thus, to minimise their risk of lung cancer, smokers in high-radon homes should both quit smoking and remediate their home. These findings accord with those from a study in Canada which also suggest that remediation can prevent radon-attributable lung cancer deaths [23].

\section{Future perspectives}

Baseline lung cancer rates differ considerably between countries, reflecting international variation in smoking patterns. These patterns are continuously changing and these changes will influence the future risks related to radon exposure (although smoking rates in Europe in 2012 [28] are similar to the USA 1993 smoking rates used here). Hence, extending these calculations would require additional information or simplifying assumptions about changes over time in the proportions of continuing, exand never-smokers, as well as the associated impact on lung cancer and all-cause mortality rates both males and females. Such calculations would be valuable in assessing how risks vary according to the different exposure distributions in different countries. However, it is not clear whether such information will be become available in the near future.

\section{APPENDIX}

Risk of exposure-induced death (REID) 
The risk of exposure induced death is the cumulative probability that an individual in the population will die from a lung cancer as a consequence of annual radon exposure received from age $a$ to age 75 years is calculated as follows:

$\operatorname{REID}(\mathrm{s}, \mathrm{a}, \mathrm{D})=\int_{a}^{74}\left[\mu_{c}(\mathrm{~s}, \mathrm{t} \mid \mathrm{a}, \mathrm{D})-\mu_{\mathrm{c}}(\mathrm{s}, \mathrm{t})\right] \mathrm{S}(\mathrm{s}, \mathrm{t} \mid \mathrm{a}, \mathrm{D}) \mathrm{dt}$

Here $\mu_{\mathrm{c}}(\mathrm{s}, \mathrm{t} \mid \mathrm{a}, \mathrm{D})$ is the annual mortality rate for lung cancer at age $t$ years for persons of gender $s$, based on an annual radon exposure D from age $a$ onwards, whilst and $\mu_{\mathrm{c}}(\mathrm{s}, \mathrm{t})$ is the corresponding mortality rate in the absence of these exposures. Under the ERR model, it is assumed that the mortality rate at age $t, y$ years after age $a$ (so that $t=a+y$ ) is given by:

$\mu_{c}(\mathrm{~s}, \mathrm{t} \mid \mathrm{a}, \mathrm{D})=\mu_{c}(\mathrm{~s}, \mathrm{t})[1+\operatorname{ERR}(\mathrm{a}, \mathrm{y}, \mathrm{D})]$

where $\mu_{\mathrm{c}}(\mathrm{s}, \mathrm{t})$ is the baseline mortality rate for lung cancer without radon exposure and $\operatorname{ERR}(\mathrm{a}, \mathrm{y}, \mathrm{D})$ is the excess relative risk:

$\mathrm{S}(\mathrm{s}, \mathrm{t} \mid \mathrm{a}, \mathrm{D})$ is the probability that an individual of gender $s$ survives to age $t$, given that this person was alive at age $a$ and based on an annual radon exposure $D$ from age $a$ onwards. For an unexposed individual, the probability of surviving to age $t$ is $\mathrm{S}(\mathrm{s}, \mathrm{t} \mid$ a). Specifically,

$\mathrm{S}(\mathrm{s}, \mathrm{t} \mid \mathrm{a}, \mathrm{D})=\exp \left[-\int_{a}^{t} \mu(\mathrm{s}, \mathrm{x} \mid \mathrm{a}, \mathrm{D}) \mathrm{dx}\right]$ 
where $\mu(\mathrm{s}, \mathrm{t} \mid \mathrm{a}, \mathrm{D})=\mu_{\mathrm{c}}(\mathrm{s}, \mathrm{t} \mid \mathrm{a}, \mathrm{D})+\sum_{l \neq c} \mu_{1}(\mathrm{~s}, \mathrm{t})$ is the mortality rate for all causes combined, i.e. a summation of mortality rates over the specific cancer type of interest and all other cancer and non-cancer causes of death.

For the purposes of this work, REID was calculated using the LRC (Lifetime Risk Calculation) software developed within the Epidemiology Department at the PHE Centre for Radiation, Chemical and Environmental Hazards. This software computes REID and LLE for individuals as well as for populations.

\section{ACKNOWLEDGMENTS}

This work was supported in part by the European Commission's $6^{\text {th }}$ Framework Programme for Research and Development Community under the Alpha-Risk project [FIP6-516483]. The authors would especially like to acknowledge Ladislav Tomasek, Dominique Laurier, Michaela Kreuzer and Margot Tirmarche for their contributions to work package 6 of this European project.

\section{REFERENCES}

[1] International Agency for Research on Cancer (IARC). Man-made Mineral Fibres and Radon. Monogr Eval Carcinog Risk Hum. 1988; 43:1-300.

[2] National Research Council, Committee on the Biological Effects of Ionizing Radiation. Health Effects of Exposure to Radon (BEIR VI). National Academy Press, Washington DC, 1999.

[3] Darby S, Hill D, Auvinen A, Barros-Dios JM, Baysson H, Bochicchio F, Deo $\mathrm{H}$, Falk R, Forastiere F, et al. Radon in homes and risk of lung cancer: 
collaborative analysis of individual data from 13 European case-control studies. BMJ 2005; 330:223.

[4] Darby S, Hill D, Deo H, Auvinen A, Barros-Dios JM, Baysson H, Bochicchio F, Falk R, Farchi S, et al. Residential radon and lung cancer--detailed results of a collaborative analysis of individual data on 7148 persons with lung cancer and 14,208 persons without lung cancer from 13 epidemiologic studies in Europe. Scand J Work Environ Health 2006; 32 Suppl 1:1-83.

[5] Lubin JH, Wang ZY, Boice, Jr. JD, Xu ZY, Blot WJ, De Wang L, Kleinerman RA. Risk of lung cancer and residential radon in China: pooled results of two studies. Int J Cancer 2004;109:132-7.

[6] Krewski D, Lubin JH, Zielinski JM, Alavanja M, Catalan VS, Field RW, et al. Residential radon and risk of lung cancer: a combined analysis of 7 North American case-control studies. Epidemiology 2005; 16:137-145.

[7] Tirmarche M, Laurier D, Bochicchio F, Cardis E, Binks K, Hofmann W, Muirhead C, Canu I. Alpha-Risk - Quantification of cancer and non-cancer risks associated with multiple chronic radiation exposures: Epidemiologic studies, organ dose calculation and risk assessment. Final scientific report. Project no. 516483. European Commission, 2009. [Available online at: ftp://ftp.cordis.europa.eu/pub/fp6-euratom/docs/arisk-final-report_en.pdf]

[8] Leuraud K, Schnelzer M, Tomasek L, Hunter N, Timarche M, Grosche B, Kreuzer M, Laurier D. Radon, smoking and lung cancer risk: results of a joint analysis of three European case-control studies among uranium miners. Radiat Res 2011; 176:375-387. 
[9] Hunter N, Muirhead CR, Tomasek L, Kreuzer M, Laurier D, Leuraud K, Schnelzer M, Grosche B, V. Placek, et al. Joint analysis of three European nested case-control studies of lung cancer among radon exposed miners: exposure restricted to below 300 WLM. Health Phys 2013; 104:282-292.

[10] Vaeth M, Pierce DA. Calculating excess lifetime risk in relative risk models. Environ Health Perspect 1990; 87:83-94.

[11] Thomas D, Darby S, Fagnani F, Hubert P, Vaeth M, Weiss K. Definition and estimation of lifetime detriment from radiation exposures: principles and methods. Health Phys 1992; 63:259-272.

[12] AGIR. Risk of solid cancers following radiation exposure: Estimates for the UK population. Report of the Independent Advisory Group on Ionising Radiation. Doc HPA, RCE-19, 1-258; 2011. [Available online at: https://www.gov.uk/government/publications/radiation-risk-of-solid-cancersfollowing-exposure

[13] Little MP, Hoel DG, Molitor J, Boice Jr. JD, Wakeford R, Muirhead CR. New models for evaluation of radiation-induced lifetime cancer risk and its uncertainty employed in the UNSCEAR 2006 report. Radiat Res 2008; 169: 660-676.

[14] United States Environment Protection Agency. EPA Assessment of Risks from Radon in Homes: 2003. [Available online at: http://www.epa.gov/radiation/docs/assessment/402-r-03-003.pdf]

[15] International Commission on Radiological Protection (ICRP). 1990 Recommendations of the International Commission on Radiological 
Protection. Ann ICRP 21, 1-201; 1991.

[16] United Nations Scientific Committee of the Effects of Atomic Radiation (UNSCEAR). Sources and effects of ionising radiation. UNSCEAR 2006 Report to the General Assembly with Scientific Annex A: Volume 1. United Nations, New York, 2008.

[17] Woloshin S, Schwartz LM, Welch HG, The risk of death by age, sex, and smoking status in the United States: putting health risks in context. J Natl Cancer Inst 2008; 100:845-853.

[18] Centres for Disease Control and Prevention (CDC), Cigarette smoking among adults, United States, 1993. Morb Mortal Wkly Report 43, 925-930; 1994.

[19] Ferlay J, Steliarova-Foucher E, Lortet-Tieulent J, Rosso S, Coebergh JWW, Comber H, Forman D, Bray F. Cancer incidence and mortality in Europe: Estimates for 40 countries in 2012. Eur J Cancer 2013; 49:1374- 1403.

[20] Catelinois O, Rogel A, Laurier D, Billon S, Hemon D, Verger P, Tirmarche M. Lung cancer attributable to indoor radon exposure in France: impact of the risk models and uncertainty analysis. Environ Health Perspect 2006; 114:13611366.

[20] Menzler S, Piller G, Gruson M, Rosario AS, Wichmann HE, Kreienbrock L. Population attributable fraction for lung cancer due to residential radon in Switzerland and Germany. Health Phys 2008; 95:179-189.

[21] Tomasek L, Rogel A, Laurier D, Tirmarche M. Dose conversion of radon exposure according to new epidemiological findings. Radiat Prot Dosim 2008; 
130:98-100.

[22] Tirmarche M, Harrison J, Laurier D, Blanchardon E, Paquet F, Marsh J. Risk of lung cancer from radon exposure: contribution of recently published studies of uranium miners. Ann ICRP 41, 368-377; 2012.

[23] Chen J, Moir D, Whyte J. Canadian population risk of radon induced lung cancer: a re-assessment based on the recent cross-Canada radon survey. Radiat Prot Dosim 2012; 152:9-13.

[24] Jemal A, Bray F, Center MM, Ferlay J, Ward E, Forman D. Global Cancer Statistics. CA Cancer J Clin 2011; 61:69-90.

[25] Danaei G, Vander Hoorn S, Lopez AD, Murray CJL, Ezzati M. (Comparative Risk Assessment collaborating group, cancers). Causes of cancer in the world: comparative risk assessment of nine behavioural and environmental risk factors. Lancet 2005; 366:1784-93.

[26] Peto R, Lopez AD, Boreham J, Thun M, Heath Jr C. Mortality from smoking in developed countries 1950-2000: indirect estimates from national vital statistics. Oxford University Press. Oxford, UK; 1994.

[27] Peterson E, Aker A, Kim J, Li Y, Brand K, Copes R. Lung cancer risk from radon in Ontario, Canada: how many lung cancers can we prevent? Cancer Causes Control 2013; 24:2013-20.

[28] Eurobarometer Report: Special Eurobarometer 385, Attitudes of Europeans towards tobacco. European Commission; 2012.

http://ec.europa.eu/health/tobacco/docs/eurobaro_attitudes_towards_tobacco_2012 
$\underline{\text { en.pdf }}$ 
Table 1: Estimated excess lifetime risk of radon-induced lung cancer death (REID) in males and females up to age 75y from age 30y, based on lifetime exposure constant at various radon concentrations using various risk models, assuming a multiplicative model for radon and smoking.

Lifetime Risk of Lung Cancer Death from Radon Exposure in Homes (\%)

\begin{tabular}{|c|c|c|c|c|c|c|c|c|c|c|c|c|c|c|c|c|}
\hline \multirow[b]{2}{*}{$\begin{array}{l}\text { Radon } \\
\text { concentra } \\
\text { tion } \\
\left(\mathbf{B q ~}^{-3}\right) \\
\end{array}$} & \multirow[b]{2}{*}{$\begin{array}{l}\text { Exposure } \\
\text { WLM/y }\end{array}$} & \multicolumn{3}{|c|}{$\begin{array}{c}\text { European case-control } \\
\text { residential model }\end{array}$} & \multicolumn{3}{|c|}{$\begin{array}{c}\text { BEIR VI (EAC) cohort miner } \\
\text { model }\end{array}$} & \multicolumn{3}{|c|}{ European cohort miner model } & \multicolumn{3}{|c|}{$\begin{array}{c}\text { European nested case-control } \\
\text { miner model } 1\end{array}$} & \multicolumn{3}{|c|}{$\begin{array}{l}\text { European nested case- } \\
\text { control miner model } 2\end{array}$} \\
\hline & & $\begin{array}{l}\text { Continuing } \\
\text { smoker }\end{array}$ & $\begin{array}{l}\text { Ex- } \\
\text { smoker } \\
\text { from } \\
\text { age 50 } \\
\end{array}$ & $\begin{array}{l}\text { Never } \\
\text { smoker }\end{array}$ & $\begin{array}{l}\text { Continui } \\
\text { ng } \\
\text { smoker }\end{array}$ & $\begin{array}{l}\text { Ex- } \\
\text { smoker } \\
\text { from } \\
\text { age 50 } \\
\end{array}$ & $\begin{array}{l}\text { Never } \\
\text { smoker }\end{array}$ & $\begin{array}{l}\text { Continui } \\
\text { ng } \\
\text { smoker }\end{array}$ & $\begin{array}{l}\text { Ex- } \\
\text { smoker } \\
\text { from } \\
\text { age 50 } \\
\end{array}$ & $\begin{array}{l}\text { Never } \\
\text { smoker }\end{array}$ & $\begin{array}{l}\text { Continui } \\
\text { ng } \\
\text { smoker }\end{array}$ & $\begin{array}{l}\text { Ex- } \\
\text { smoker } \\
\text { from } \\
\text { age 50 } \\
\end{array}$ & $\begin{array}{l}\text { Never } \\
\text { smoker }\end{array}$ & $\begin{array}{l}\text { Contin } \\
\text { uing } \\
\text { smoker }\end{array}$ & $\begin{array}{l}\text { Ex- } \\
\text { smoker } \\
\text { from } \\
\text { age 50 } \\
\end{array}$ & $\begin{array}{l}\text { Never } \\
\text { smoker }\end{array}$ \\
\hline \multicolumn{17}{|l|}{ Males } \\
\hline 20 & 0.09 & 0.31 & 0.14 & 0.02 & 0.70 & 0.32 & 0.04 & 0.46 & 0.22 & 0.03 & 0.45 & 0.21 & 0.03 & 0.34 & 0.17 & 0.02 \\
\hline 50 & 0.22 & 0.76 & 0.34 & 0.06 & 1.70 & 0.79 & 0.11 & 1.12 & 0.53 & 0.08 & 1.11 & 0.51 & 0.07 & 0.83 & 0.41 & 0.06 \\
\hline 80 & 0.35 & 1.20 & 0.55 & 0.08 & 2.68 & 1.25 & 0.17 & 1.77 & 0.84 & 0.12 & 1.75 & 0.82 & 0.11 & 1.32 & 0.64 & 0.09 \\
\hline 100 & 0.44 & 1.51 & 0.69 & 0.10 & 3.36 & 1.57 & 0.21 & 2.22 & 1.06 & 0.15 & 2.20 & 1.02 & 0.14 & 1.65 & 0.81 & 0.11 \\
\hline 200 & 0.88 & 2.98 & 1.38 & 0.19 & 6.55 & 3.11 & 0.42 & 4.37 & 2.11 & 0.30 & 4.32 & 2.03 & 0.27 & 3.26 & 1.61 & 0.22 \\
\hline 400 & 1.76 & 5.82 & 2.72 & 0.39 & 12.5 & 6.10 & 0.85 & 8.45 & 4.15 & 0.60 & 8.38 & 4.01 & 0.54 & 6.38 & 3.19 & 0.45 \\
\hline 600 & 2.64 & 8.53 & 4.05 & 0.58 & 17.9 & 8.97 & 1.27 & 12.3 & 6.14 & 0.90 & 12.2 & 5.94 & 0.81 & 9.35 & 4.74 & 0.67 \\
\hline \multicolumn{17}{|l|}{ Females } \\
\hline 20 & 0.09 & 0.24 & 0.12 & 0.03 & 0.56 & 0.28 & 0.05 & 0.36 & 0.19 & 0.04 & 0.37 & 0.18 & 0.04 & 0.28 & 0.15 & 0.03 \\
\hline 50 & 0.22 & 0.59 & 0.29 & 0.06 & 1.36 & 0.69 & 0.13 & 0.89 & 0.46 & 0.09 & 0.89 & 0.44 & 0.09 & 0.67 & 0.36 & 0.06 \\
\hline 80 & 0.35 & 0.94 & 0.46 & 0.10 & 2.16 & 1.09 & 0.21 & 1.40 & 0.73 & 0.14 & 1.41 & 0.70 & 0.14 & 1.07 & 0.56 & 0.10 \\
\hline 100 & 0.44 & 1.18 & 0.58 & 0.13 & 2.70 & 1.37 & 0.27 & 1.76 & 0.91 & 0.18 & 1.77 & 0.88 & 0.17 & 1.34 & 0.73 & 0.13 \\
\hline 200 & 0.88 & 2.33 & 1.16 & 0.25 & 5.31 & 2.71 & 0.53 & 3.48 & 1.82 & 0.36 & 3.50 & 1.76 & 0.34 & 2.65 & 1.44 & 0.25 \\
\hline 400 & 1.76 & 4.59 & 2.30 & 0.50 & 10.3 & 5.34 & 1.06 & 6.81 & 3.59 & 0.73 & 6.90 & 3.48 & 0.68 & 5.22 & 2.86 & 0.51 \\
\hline 600 & 2.64 & 6.79 & 3.43 & 0.75 & 14.93 & 7.88 & 1.58 & 10.00 & 5.33 & 1.08 & 10.10 & 5.17 & 1.02 & 7.71 & 4.26 & 0.76 \\
\hline
\end{tabular}

$a$ : Based on radon concentrations in homes occupied during previous 5-34 years (derived from Eq.5). 
Table 2: Estimated risk (\%) of radon-induced lung cancer death (REID) in males and females up to age 75 years from age 30 years for continuing smokers, ex-smokers from age 50 and never smokers, using model 2 from the European case-control miner analysis (Eq. 3b), based on a multiplicative and a sub-multiplicative relationship between radon exposure and smoking.

\begin{tabular}{|c|c|c|c|c|}
\hline \multirow[b]{3}{*}{$\begin{array}{l}\text { Radon } \\
\text { concentration } \\
\left(\mathbf{B q ~}^{-3}\right)\end{array}$} & \multicolumn{4}{|c|}{ European nested case-control miner model 2} \\
\hline & \multicolumn{2}{|c|}{ Multiplicative $^{a}$} & \multicolumn{2}{|c|}{ Sub-multiplicative $^{b}$} \\
\hline & $\begin{array}{l}\text { Continuing } \\
\text { Smoker }\end{array}$ & $\begin{array}{l}\text { Never } \\
\text { smoker }\end{array}$ & $\begin{array}{l}\text { Continuing } \\
\text { Smoker }\end{array}$ & $\begin{array}{l}\text { Never } \\
\text { smoker }\end{array}$ \\
\hline \multicolumn{5}{|l|}{ Males } \\
\hline 20 & 0.34 & 0.02 & 0.26 & 0.03 \\
\hline 50 & 0.83 & 0.06 & 0.62 & 0.08 \\
\hline 80 & 1.32 & 0.09 & 0.99 & 0.13 \\
\hline 100 & 1.65 & 0.11 & 1.24 & 0.16 \\
\hline 200 & 3.26 & 0.22 & 2.45 & 0.33 \\
\hline 400 & 6.38 & 0.45 & 4.79 & 0.65 \\
\hline 600 & 9.35 & 0.67 & 7.01 & 0.98 \\
\hline \multicolumn{5}{|l|}{ Females } \\
\hline 20 & 0.28 & 0.03 & 0.21 & 0.04 \\
\hline 50 & 0.67 & 0.06 & 0.50 & 0.10 \\
\hline 80 & 1.07 & 0.10 & 0.80 & 0.15 \\
\hline 100 & 1.34 & 0.13 & 1.01 & 0.19 \\
\hline 200 & 2.65 & 0.25 & 1.99 & 0.39 \\
\hline 400 & 5.22 & 0.51 & 3.91 & 0.77 \\
\hline 600 & 7.71 & 0.76 & 5.78 & 1.16 \\
\hline
\end{tabular}

$a$ : The same ERR/WLM is applied to continuing and never-smokers.

$b$ : Adjusted by multiplying the baseline ERR/WLM by 0.75 for continuing smokers and by 1.5 for neversmokers. 
Table 3: Impact of radon remediation from age 50 or 60 years on the estimated risk (\%) of radon-induced lung cancer death (REID) in males up to age 75 years, based on initial radon concentrations of 200,400 and $600 \mathrm{~Bq} \mathrm{~m}^{-3}$ using various risk models and assuming a multiplicative model for radon and smoking.

\section{Lifetime Risk of Lung Cancer Death from Radon Exposure in Homes (\%)}

\begin{tabular}{|c|c|c|c|c|c|c|c|c|c|c|c|c|c|c|c|}
\hline \multirow[b]{2}{*}{$\begin{array}{l}\text { Initial radon } \\
\text { concentration }\end{array}$} & \multicolumn{3}{|c|}{$\begin{array}{l}\text { European case-control } \\
\text { residential model }\end{array}$} & \multicolumn{3}{|c|}{$\begin{array}{l}\text { BEIR VI (EAC) cohort } \\
\text { miner model }\end{array}$} & \multicolumn{3}{|c|}{ European cohort miner model } & \multicolumn{3}{|c|}{$\begin{array}{l}\text { European nested case- } \\
\text { control miner model } 1\end{array}$} & \multicolumn{3}{|c|}{$\begin{array}{c}\text { European nested case-control } \\
\text { miner model } 2\end{array}$} \\
\hline & $\begin{array}{l}\text { Continui } \\
\text { ng } \\
\text { smoker }\end{array}$ & $\begin{array}{l}\text { Ex- } \\
\text { smoker } \\
\text { from } \\
\text { age 50 } \\
\end{array}$ & $\begin{array}{l}\text { Never } \\
\text { smoker }\end{array}$ & $\begin{array}{l}\text { Continuin } \\
\text { g } \\
\text { smoker }\end{array}$ & $\begin{array}{l}\text { Ex- } \\
\text { smoker } \\
\text { from } \\
\text { age } 50 \\
\end{array}$ & $\begin{array}{l}\text { Never } \\
\text { smoker }\end{array}$ & $\begin{array}{l}\text { Continui } \\
\text { ng } \\
\text { smoker }\end{array}$ & $\begin{array}{l}\text { Ex- } \\
\text { smoker } \\
\text { from } \\
\text { age 50 }\end{array}$ & $\begin{array}{l}\text { Never } \\
\text { smoker }\end{array}$ & $\begin{array}{l}\text { Continui } \\
\text { ng } \\
\text { smoker }\end{array}$ & $\begin{array}{l}\text { Ex- } \\
\text { smoker } \\
\text { from } \\
\text { age 50 }\end{array}$ & $\begin{array}{l}\text { Never } \\
\text { smoker }\end{array}$ & $\begin{array}{l}\text { Continuin } \\
\text { g } \\
\text { smoker }\end{array}$ & $\begin{array}{l}\text { Ex- } \\
\text { smoker } \\
\text { from } \\
\text { age 50 }\end{array}$ & $\begin{array}{l}\text { Never } \\
\text { smoker }\end{array}$ \\
\hline$\frac{200 \mathrm{~Bq} \mathrm{~m}^{-3}}{{\text { (without remediation })^{a}}^{a}}$ & 2.98 & 1.38 & 0.19 & 6.55 & 3.11 & 0.42 & 4.37 & 2.11 & 0.30 & 4.32 & 2.03 & 0.27 & 3.26 & 1.61 & 0.22 \\
\hline $\begin{array}{l}\text { (with remediation from } \\
\text { age } 60 \text { years) } b\end{array}$ & 2.81 & 1.29 & 0.18 & 6.28 & 2.98 & 0.40 & 4.07 & 1.95 & 0.28 & 4.11 & 1.92 & 0.25 & 3.07 & 1.52 & 0.21 \\
\hline $\begin{array}{l}\text { (with remediation from } \\
\text { age } 50 \text { years) }{ }^{c}\end{array}$ & 2.40 & 1.09 & 0.15 & 5.48 & 2.61 & 0.35 & 3.41 & 1.65 & 0.23 & 3.49 & 1.63 & 0.21 & 2.71 & 1.37 & 0.19 \\
\hline$\frac{400 \mathrm{~Bq} \mathrm{~m}^{-3}}{{\text { (without remediation })^{a}}^{a}}$ & 5.82 & 2.72 & 0.39 & 12.5 & 6.10 & 0.85 & 8.45 & 4.15 & 0.60 & 8.38 & 4.01 & 0.54 & 6.38 & 3.19 & 0.45 \\
\hline $\begin{array}{l}\text { (with remediation from } \\
\text { age } 60 \text { years) }{ }^{b}\end{array}$ & 5.33 & 2.47 & 0.34 & 11.8 & 5.71 & 0.78 & 7.62 & 3.70 & 0.52 & 7.79 & 3.69 & 0.48 & 5.84 & 2.93 & 0.41 \\
\hline $\begin{array}{l}\text { (with remediation from } \\
\text { age } 50 \text { years) }\end{array}$ & 4.15 & 1.90 & 0.26 & 9.54 & 4.64 & 0.63 & 5.74 & 2.81 & 0.40 & 6.00 & 2.84 & 0.37 & 4.80 & 2.47 & 0.35 \\
\hline$\frac{600 \mathrm{~Bq} \mathrm{~m}^{-3}}{{\text { (without remediation })^{a}}^{a}}$ & 8.53 & 4.05 & 0.58 & 17.9 & 8.97 & 1.27 & 12.3 & 6.14 & 0.90 & 12.2 & 5.94 & 0.81 & 9.35 & 4.74 & 0.67 \\
\hline $\begin{array}{l}\text { (with remediation from } \\
\text { age } 60 \text { years) }\end{array}$ & 7.75 & 3.63 & 0.50 & 16.8 & 8.34 & 1.15 & 11.0 & 5.40 & 0.91 & 11.3 & 5.41 & 0.71 & 8.50 & 4.32 & 0.60 \\
\hline $\begin{array}{l}\text { (with remediation from } \\
\text { age } 50 \text { years) }{ }^{c}\end{array}$ & 5.86 & 2.69 & 0.37 & 13.4 & 6.62 & 0.91 & 8.00 & 3.96 & 0.56 & 8.42 & 4.02 & 0.52 & 6.83 & 3.56 & 0.50 \\
\hline
\end{tabular}

$a$ : Exposure at the same concentration up to age 75 years from 30 years; $b$ : Exposure at the initial concentration up to age 59 years from 30 years and at 100 Bq $\mathrm{m}^{-3}$ from age 60 years up to age 75 years; $c$ : Exposure at the initial concentration up to age 49 years from 30 years and at $100 \mathrm{~Bq} \mathrm{~m}^{-3}$ from age 50 years up to age 75 years. 
Table 4: Impact of radon remediation from age 50 or 60 years on the estimated risk (\%) of radon-induced lung cancer death (REID) in females up to age 75 years, based on initial radon concentrations of 200,400 and $600 \mathrm{~Bq} \mathrm{~m}^{-3}$ using various risk models and assuming a multiplicative model for radon and smoking.

Lifetime Risk of Lung Cancer Death from Radon Exposure in Homes (\%)

\begin{tabular}{|c|c|c|c|c|c|c|c|c|c|c|c|c|c|c|c|}
\hline \multirow[b]{2}{*}{ Initial radon concentration } & \multicolumn{3}{|c|}{$\begin{array}{c}\text { European case-control } \\
\text { residential model }\end{array}$} & \multicolumn{3}{|c|}{$\begin{array}{c}\text { BEIR VI (EAC) cohort } \\
\text { miner model } \\
\end{array}$} & \multicolumn{3}{|c|}{ European cohort miner model } & \multicolumn{3}{|c|}{$\begin{array}{l}\text { European nested case- } \\
\text { control miner model } 1\end{array}$} & \multicolumn{3}{|c|}{$\begin{array}{c}\text { European nested case-control } \\
\text { miner model } 2 \\
\end{array}$} \\
\hline & $\begin{array}{l}\text { Continui } \\
\text { ng } \\
\text { smoker }\end{array}$ & $\begin{array}{l}\text { Ex- } \\
\text { smoker } \\
\text { from } \\
\text { age 50 } \\
\end{array}$ & $\begin{array}{l}\text { Never } \\
\text { smoker }\end{array}$ & $\begin{array}{l}\text { Continuin } \\
\text { g } \\
\text { smoker }\end{array}$ & $\begin{array}{l}\text { Ex- } \\
\text { smoker } \\
\text { from } \\
\text { age 50 } \\
\end{array}$ & $\begin{array}{l}\text { Never } \\
\text { smoker }\end{array}$ & $\begin{array}{l}\text { Continui } \\
\text { ng } \\
\text { smoker }\end{array}$ & $\begin{array}{l}\text { Ex- } \\
\text { smoker } \\
\text { from } \\
\text { age 50 } \\
\end{array}$ & $\begin{array}{l}\text { Never } \\
\text { smoker }\end{array}$ & $\begin{array}{l}\text { Continui } \\
\text { ng } \\
\text { smoker }\end{array}$ & $\begin{array}{l}\text { Ex- } \\
\text { smoker } \\
\text { from } \\
\text { age 50 } \\
\end{array}$ & $\begin{array}{l}\text { Never } \\
\text { smoker }\end{array}$ & $\begin{array}{l}\text { Continuin } \\
\text { g } \\
\text { smoker }\end{array}$ & $\begin{array}{l}\text { Ex- } \\
\text { smoker } \\
\text { from } \\
\text { age 50 } \\
\end{array}$ & $\begin{array}{l}\text { Never } \\
\text { smoker }\end{array}$ \\
\hline$\frac{200 \mathrm{~Bq} \mathrm{~m}^{-3}}{{\text { (without remediation })^{a}}}$ & 2.33 & 1.16 & 0.25 & 5.31 & 2.71 & 0.53 & 3.48 & 1.82 & 0.36 & 3.50 & 1.76 & 0.34 & 2.65 & 1.44 & 0.25 \\
\hline $\begin{array}{l}\text { (with remediation from } \\
\text { age } 60 \text { years) }{ }^{b}\end{array}$ & 2.20 & 1.09 & 0.23 & 5.10 & 2.60 & 0.50 & 3.26 & 1.69 & 0.33 & 3.34 & 1.67 & 0.32 & 2.51 & 1.37 & 0.24 \\
\hline $\begin{array}{l}\text { (with remediation from } \\
\text { age } 50 \text { years) }{ }^{c}\end{array}$ & 1.89 & 0.93 & 0.20 & 4.46 & 2.29 & 0.43 & 2.75 & 1.44 & 0.27 & 2.85 & 1.43 & 0.27 & 2.22 & 1.24 & 0.21 \\
\hline$\frac{400 \mathrm{~Bq} \mathrm{~m}^{-3}}{{\text { (without remediation })^{a}}^{a}}$ & 4.59 & 2.30 & 0.50 & 10.3 & 5.34 & 1.06 & 6.81 & 3.59 & 0.73 & 6.90 & 3.48 & 0.68 & 5.22 & 2.86 & 0.51 \\
\hline $\begin{array}{l}\text { (with remediation from } \\
\text { age } 60 \text { years) }{ }^{b}\end{array}$ & 4.22 & 2.09 & 0.44 & 9.70 & 5.00 & 0.97 & 6.17 & 3.21 & 0.63 & 6.40 & 3.21 & 0.62 & 4.81 & 2.65 & 0.46 \\
\hline $\begin{array}{l}\text { (with remediation from } \\
\text { age } 50 \text { years) }\end{array}$ & 3.30 & 1.62 & 0.34 & 7.88 & 4.10 & 0.77 & 4.68 & 2.48 & 0.46 & 4.96 & 2.50 & 0.46 & 3.97 & 2.26 & 0.37 \\
\hline$\frac{600 \mathrm{~Bq} \mathrm{~m}^{-3}}{{\text { (without remediation })^{a}}^{a}}$ & 6.79 & 3.43 & 0.75 & 14.9 & 7.88 & 1.58 & 10.00 & 5.33 & 1.08 & 10.1 & 5.17 & 1.02 & 7.71 & 4.26 & 0.76 \\
\hline $\begin{array}{l}\text { (with remediation from } \\
\text { age } 60 \text { years) }\end{array}$ & 6.18 & 3.08 & 0.65 & 14.0 & 7.34 & 1.44 & 8.97 & 4.71 & 0.93 & 9.34 & 4.73 & 0.91 & 7.05 & 3.91 & 0.67 \\
\hline $\begin{array}{l}\text { (with remediation from } \\
\text { age } 50 \text { years) }{ }^{c}\end{array}$ & 4.68 & 2.30 & 0.48 & 11.1 & 5.88 & 1.10 & 6.57 & 3.50 & 0.64 & 7.02 & 3.56 & 0.65 & 5.68 & 3.27 & 0.53 \\
\hline
\end{tabular}

$a$ : Exposure at the same concentration up to age 75 years from 30 years; $b$ : Exposure at the initial concentration up to age 59 years from 30 years and at $100 \mathrm{~Bq} \mathrm{~m}^{-3}$ from age 60 years up to age 75 years; $c$ : Exposure at the initial concentration up to age 49 years from 30 years and at $100 \mathrm{~Bq} \mathrm{~m}^{-3}$ from age 50 years up to age 75 years. 

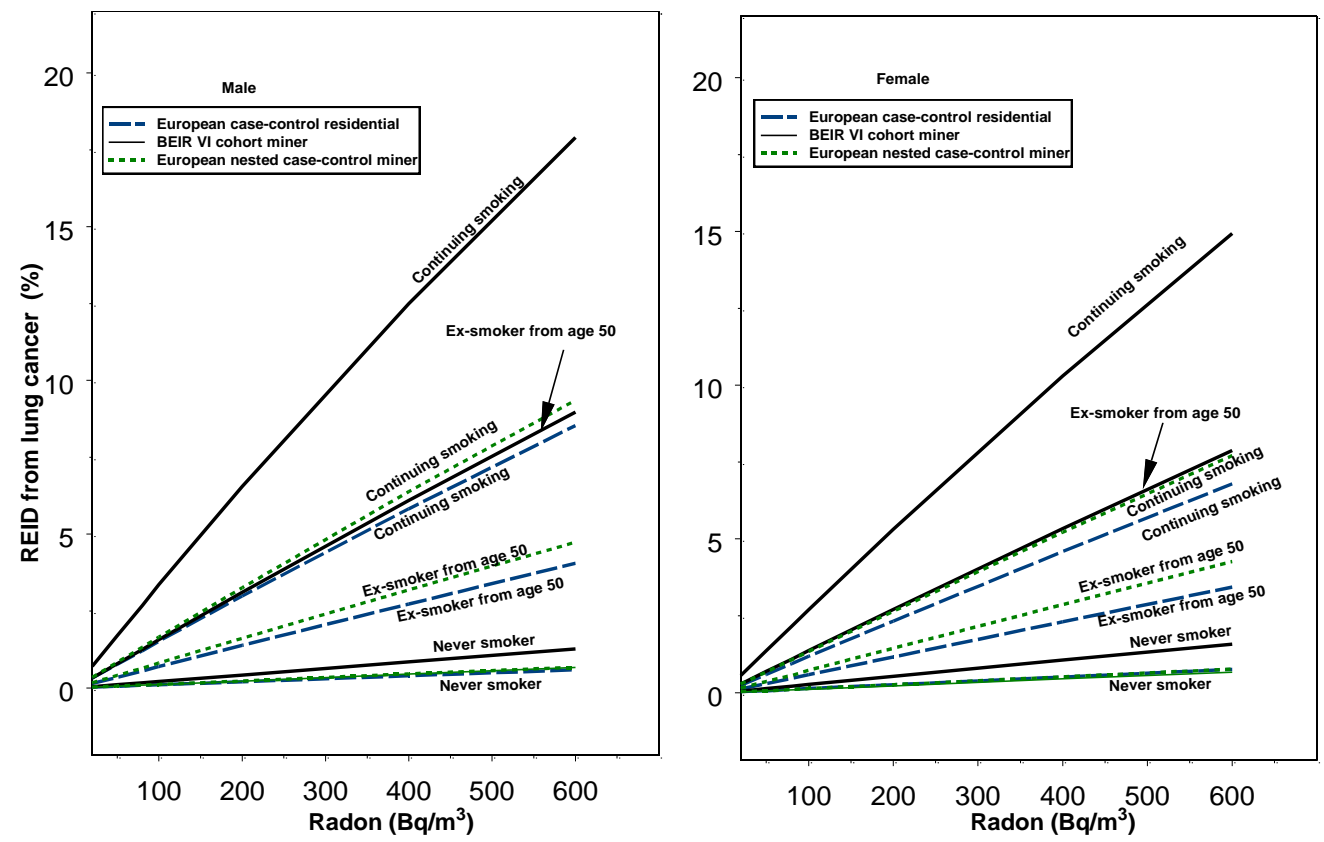

Figure 1: Lung cancer risk from age $30 \mathrm{y}$ up to age $75 \mathrm{y}$, based on lifetime exposure constant at various radon concentrations models, assuming a multiplicative model for radon and smoking. 